\title{
FY16 Safeguards Technology Cart- Portable Mass Spectrometer Project Final Report
}

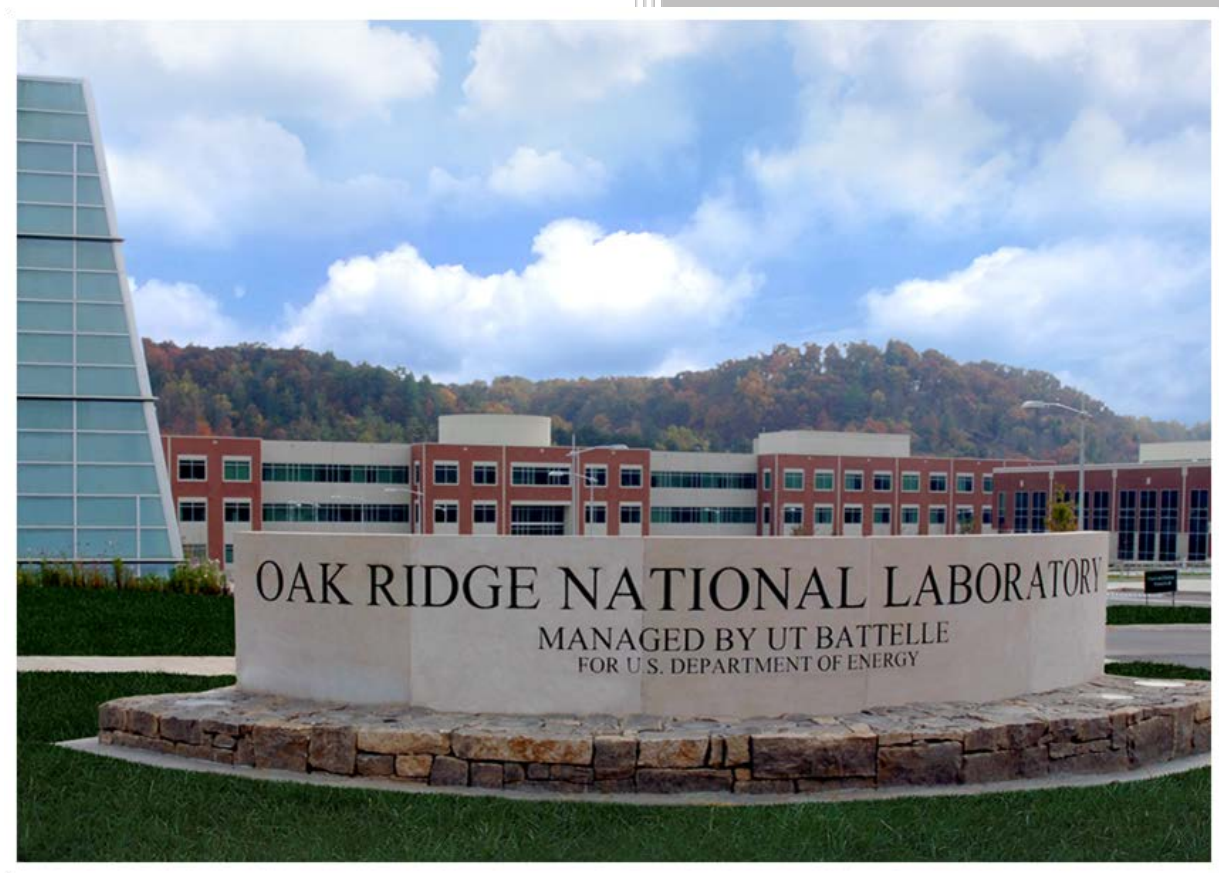

Approved for public release. Distribution is unlimited.

Cyril V. Thompson

William B. Whitten

February 2017 


\title{
DOCUMENT AVAILABILITY
}

Reports produced after January 1, 1996, are generally available free via US Department of Energy (DOE) SciTech Connect.

\section{Website http://www.osti.gov/scitech/}

Reports produced before January 1, 1996, may be purchased by members of the public from the following source:

\author{
National Technical Information Service \\ 5285 Port Royal Road \\ Springfield, VA 22161 \\ Telephone 703-605-6000 (1-800-553-6847) \\ TDD 703-487-4639 \\ Fax 703-605-6900 \\ E-mail info@ntis.gov \\ Website http://classic.ntis.gov/
}

Reports are available to DOE employees, DOE contractors, Energy Technology Data Exchange representatives, and International Nuclear Information System representatives from the following source:

Office of Scientific and Technical Information

PO Box 62

Oak Ridge, TN 37831

Telephone 865-576-8401

Fax 865-576-5728

E-mail reports@osti.gov

Website http://www.osti.gov/contact.html

This report was prepared as an account of work sponsored by an agency of the United States Government. Neither the United States Government nor any agency thereof, nor any of their employees, makes any warranty, express or implied, or assumes any legal liability or responsibility for the accuracy, completeness, or usefulness of any information, apparatus, product, or process disclosed, or represents that its use would not infringe privately owned rights. Reference herein to any specific commercial product, process, or service by trade name, trademark, manufacturer, or otherwise, does not necessarily constitute or imply its endorsement, recommendation, or favoring by the United States Government or any agency thereof. The views and opinions of authors expressed herein do not necessarily state or reflect those of the United States Government or any agency thereof. 
Chemical Sciences Division

FY16 SAFEGUARDS TECHNOLOGY PROJECT CART PORTABLE MASS SPECTROMETER FINAL REPORT

Cyril V. Thompson

William B. Whitten

Date Published: February 2017

Prepared by

OAK RIDGE NATIONAL LABORATORY

Oak Ridge, TN 37831-6283

managed by

UT-BATTELLE, LLC

for the

US DEPARTMENT OF ENERGY

under contract DE-AC05-00OR22725 


\section{CONTENTS}

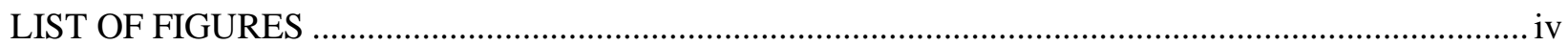

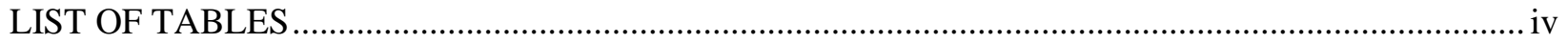

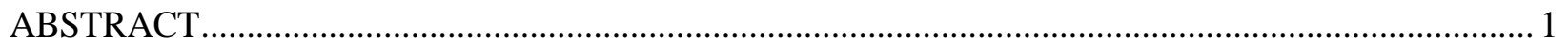

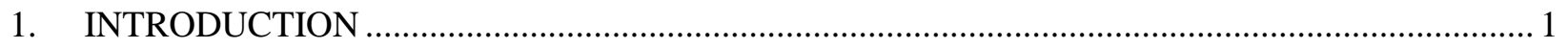

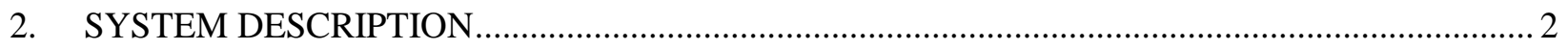

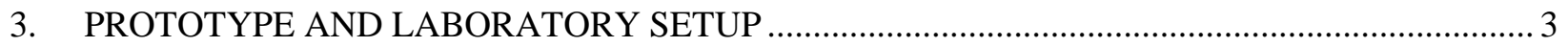

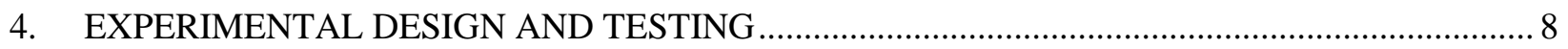

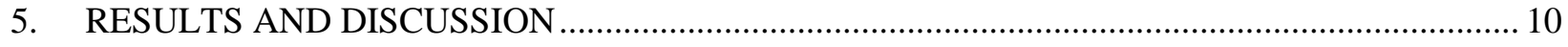

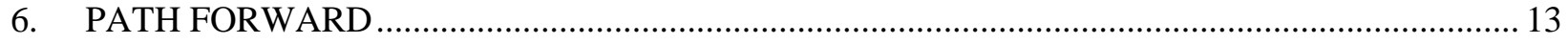

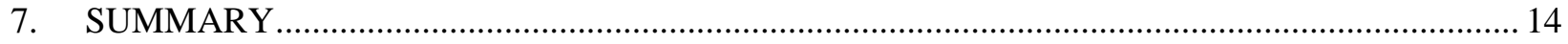

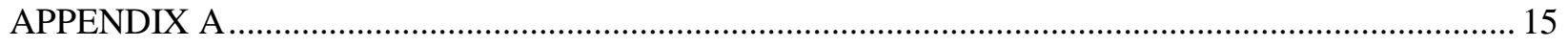




\section{LIST OF FIGURES}

Figure 1. Cart portable mass spectrometer-retrofit: (a) side view, (b) side view-modified vacuum chamber, (c) front end-cover removed, vacuum system, (d) back view, (e) modified analyzer — end view, (f) modified analyzer — side view................................................. 4

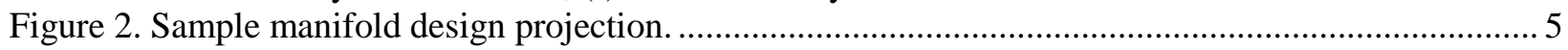

Figure 3. Process flowchart of sample manifold pneumatics. .............................................................. 5

Figure 4. Sample manifold internals: (a) manifold—front view, (b) manifold—left side view, (c) manifold—right side view, (d) manifold—back view.

Figure 5. Cart portable MS (left) and sample manifold (right) in MBA hood........................................... 8

Figure 6. Spectra from 1 hour sample experiment.................................................................................. 11

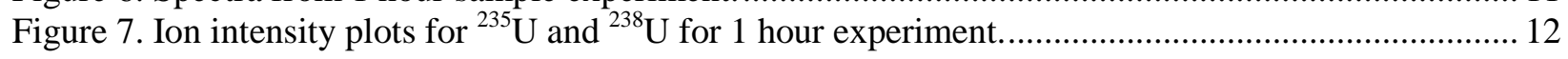

Figure 8. Experiment to monitor sample manifold carry-over. ............................................................. 13

\section{LIST OF TABLES}

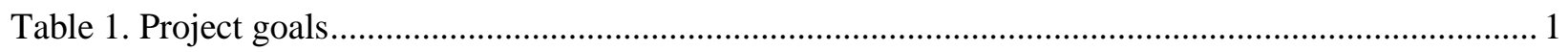

Table 2. PLC sequences for valve control and sample manifold operation............................................... 6 


\begin{abstract}
A cart-portable mass spectrometer (MS) has been developed by the Oak Ridge National Laboratory project for the NNSA Office of Nonproliferation and Arms Control. The cart portable MS system is based on a Thermo ITQ ion trap mass spectrometer (referred to simply as the ITQ) and is designed for the field analysis of ${ }^{235} \mathrm{U} /{ }^{238} \mathrm{U}$ ratios in $\mathrm{UF}_{6}$. Experiments have revealed that combining $\mathrm{CO}_{2}$ with $\mathrm{UF}_{6}$ and introducing the mixture to the MS appeared to increase the ionization efficiency and, thus, reduce the amount of $\mathrm{UF}_{6}$ needed for an analysis while also reducing the corrosive effects of the sample on internal MS components. However, initial results indicated that mixing parameters should be closely controlled to ensure reproducible results. To this end, a sample manifold (SM) that would ensure the precise mixing of $\mathrm{UF}_{6}$ and $\mathrm{CO}_{2}$ was designed and constructed. A number of experiments were conducted to determine optimum SM and MS conditions which would provide the most stable isotope ratio analysis. The principal objective of the project was to deliver a retrofit ITQ mass spectrometer operating with a SM capable of achieving a variation in precision of less than $1 \%$ over 1 hour of sampling. Data was acquired with that demonstrated the desired precision with a measured variation of 0.5 to $0.8 \%$ over 1 hour of sampling for multiple sample runs.
\end{abstract}

\title{
1. INTRODUCTION
}

Several project tasks conducted at Oak Ridge National Laboratory over several years were aimed at developing a cart portable MS for deployment and analysis of $\mathrm{UF}_{6}$ in field settings. Prior tasks in the project have included:

- minimizing instrument power requirements by reducing the size of the pumping system

- incorporating a smaller vacuum chamber for the analyzer

- and incorporating the support gases within the MS housing envelope

In previous project studies, electron capture negative ion (ECI) detection of $\mathrm{UF}_{6}$ was shown to provide a much better analytical result than the positive electron impact (EI) mode, as it minimized fragmentation of the analyte and eliminated mass spectral interference due to reaction products of trapped ions with residual neutral species such as water vapor. A more recent analytical development involved incorporation of $\mathrm{CO}_{2}$ into the $\mathrm{UF}_{6}$ sample, with $\mathrm{CO}_{2}$ acting both as an electron moderating agent and a dilution gas. Early experiments with added $\mathrm{CO}_{2}$ were promising, although no complete study of the effects and benefits was made at that time. To fully characterize the benefits of $\mathrm{CO}_{2}$ as an addition gas, an SM was suggested as a means of easily controlling mixing and introduction of the samples to the MS.

Project goals recommended through interaction with personnel from the Nondestructive Assay Section of the International Atomic Energy Agency (IAEA) are summarized in Table 1.

Table 1. Project goals

1. Sample manifold should be designed and tested

a. Accommodate one sample and two certified references of $\mathrm{UF}_{6}$

b. Support preparation of a sampling volume at fixed pressure

c. Support dilution in $\mathrm{CO}_{2}$ at a prescribed rate

d. Tightly control sample flow to the mass spectrometer

e. Support removal of HF as necessary

2. Systematically explore variability of the isotope ratio vs all identified parameters

3. Identify optimized reproducible operating parameters 
4. Develop software tools to automate data reduction and QA analysis of results

5. Develop and validate a robust procedure for field use

6. Demonstrate in Vienna - train final users

This project began in 2015 with the support of the Safeguards Technology Development Sub-Program (SGTech) in the NNSA Office of Nonproliferation and Arms Control.

\section{PROJECT DESCRIPTION}

The ORNL project was designed to accommodate IAEA requests, and included the following elements.

1. ITQ Retrofit (purchased instrument) and checkout: Outfit the new ITQ with all modifications, including a custom $1 / 4$-sized vacuum chamber, He gas supply, and modified pumping system. Test the new instrument with surrogate gases and then with $\mathrm{UF}_{6}$ to confirm it matches specifications of the original instrument and can operate in negative ion detection mode.

2. Design/Construction of $\mathbf{U F}_{6}$ Sample Manifold: Construct a manifold with adequate mixing volumes, vacuum system, inlets for two standards and a sample, and a $\mathrm{CO}_{2}$ source in order to accurately and consistently mix $\mathrm{CO}_{2}$ with $\mathrm{UF}_{6}$ standards and samples before introducing them to the ITQ. Performance test, characterize, and use the manifold as a sample source for the instrument optimization in Task 3.

3. Instrument Tuning/Optimization: Tune and optimize the ITQ instrument parameters which were identified as needing control/optimization during the September 2015 IAEA visit. These parameters include $\mathrm{RF}$ ramp rate, $\mathrm{RF}$ sample rate, mass range, $\mathrm{CO}_{2} / \mathrm{UF}_{6}$ ratio, microscans, temperature, sample pressure, He pressure, multiplier life/voltage, and Ion volume selection. This was the most labor intensive portion of the project and required extensive access to the ORNL UF 6 test loops or standalone use of the SM from Task 2. The latter option was highly desirable, as it provided unfettered access to $\mathrm{UF}_{6}$ samples for parameter characterization. It is worth noting that without reducing the amount of corrosive $\mathrm{UF}_{6}$ sample needed and mixing it with $\mathrm{CO}_{2}$, this task could have consumed a number of both filaments and electron multipliers.

4. Gas Absorbent in Vacuum: Reduce the amount of extraneous $\mathrm{UF}_{6}$ and $\mathrm{HF}$ in the vacuum system to significantly extend the lifetime of the electron multiplier by introducing porous stainless steel containers holding activated alumina, which acts as an absorbent of $\mathrm{UF}_{6}$ and $\mathrm{HF}$.

5. Independent $\mathrm{CO}_{2}$ Introduction/Filament Protection: Develop a hardware method for filament protection via independent $\mathrm{CO} 2$ introduction directly over the filament and into the ion volume. If $\mathrm{CO}_{2}$ is flowed over the filament and into the ion volume (after $\mathrm{UF}_{6}$ sample introduction), the corresponding reduction in exposure to $\mathrm{UF}_{6} / \mathrm{HF}$ could increase filament lifetimes substantially.

6. Software Development/Data Output: Customize software for post-processing and report output . The original source code is provided by Thermo in their Software Development Kit (SDK) to facilitate software modifications. 


\section{PROTOTYPE AND LABORATORY SETUP}

ITQ Retrofit: A Thermo ITQ instrument (ITQ) was purchased, parts for the modified design - a $1 / 4$ size vacuum chamber, He gas supply, and modified pumping system - were fabricated and incorporated into the ITQ. The modified instrument (Figure 1) was tested and confirmed to function well in normal operating modes using the instrument calibration gas. The weight of the as-configured MS is 80 lbs down from 150 lbs. for the COTS system (which includes a rotary vane vacuum pump).

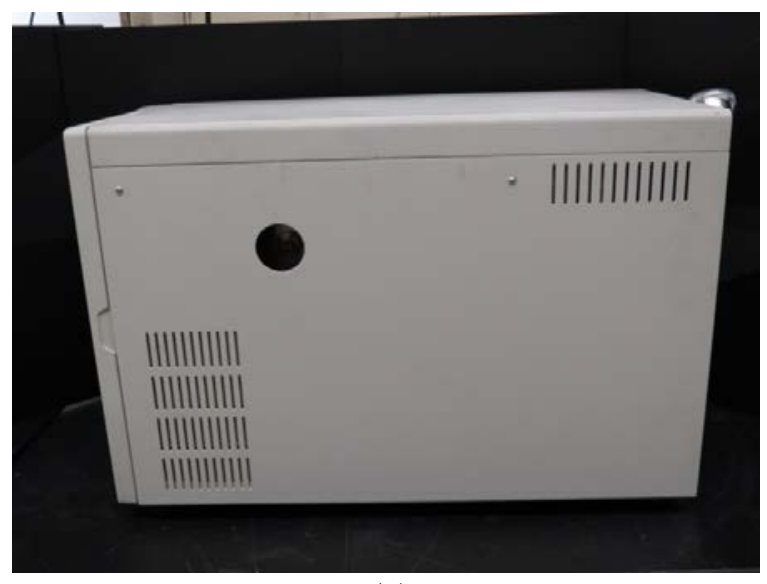

(a)

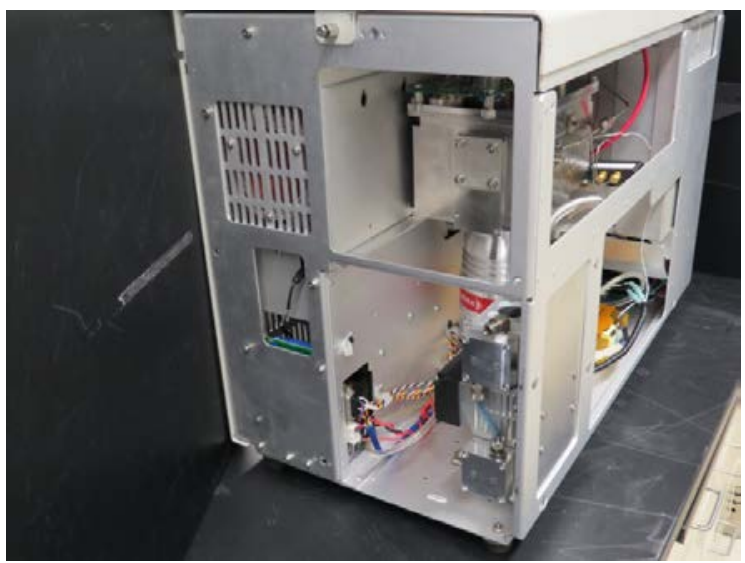

(c)

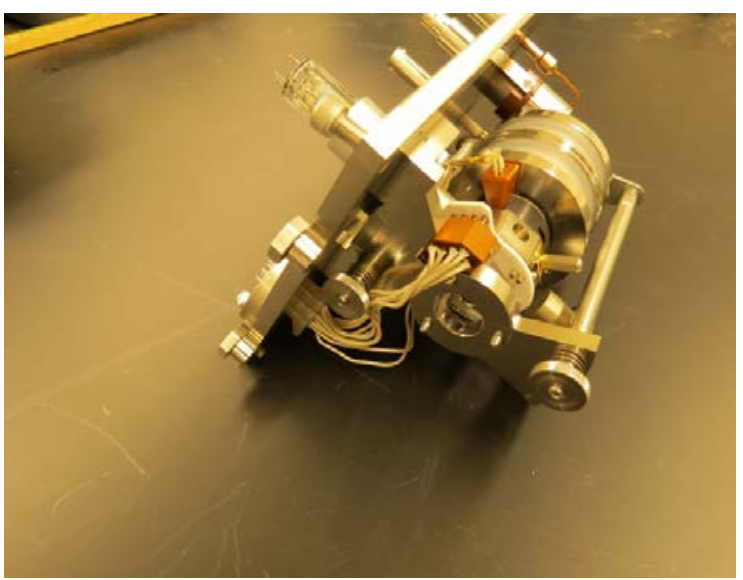

(e)

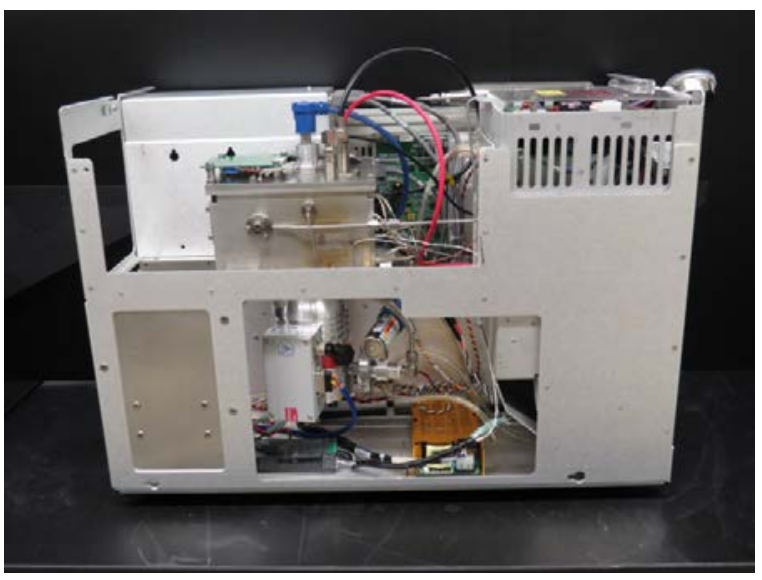

(b)

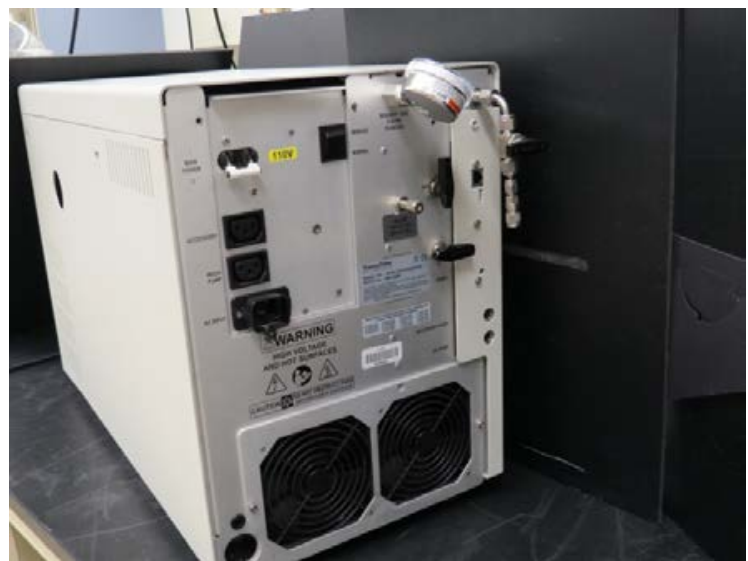

(d)

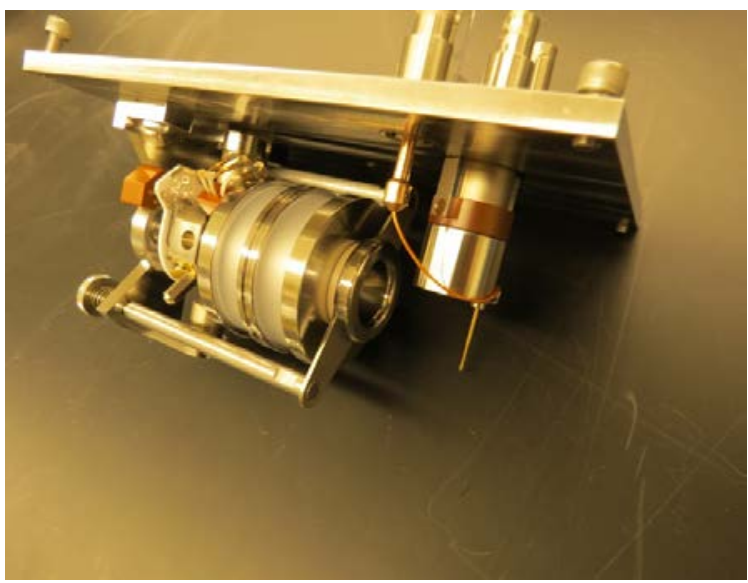

(f) 
Figure 1. Cart portable mass spectrometer—retrofit: (a) side view, (b) side view—modified vacuum chamber, (c) front end-cover removed, vacuum system, (d) back view, (e) modified analyzer—end view, (f) modified analyzer-side view.

Design/Construction of $\mathbf{U F}_{6}$ Sample Manifold (SM): The purpose of the SM, as previously stated, is to allow mixing $\mathrm{CO}_{2}$ with $\mathrm{UF}_{6}$ samples and standards in a regimented fashion, followed by release of the mixed gas to the MS (Figure 2). Initial experiments indicated a significant benefit from using this mixture but were not extensive enough to specify the optimum ratio of $\mathrm{CO}_{2}: \mathrm{UF}_{6}$.

The SM was initially designed with input from IAEA personnel to meet their requested specifications. The SM incorporated one sample mixing chamber (with provision for $\mathrm{UF}_{6}$ sample input from a P-10 tube or other suitable container) and one standard mixing chamber (with provision for input from two separate $\mathrm{UF}_{6}$ standards contained in P-10 tubes or comparable containers).

Two $\mathrm{UF}_{6}$ standards — one at a low ratio of ${ }^{235} \mathrm{U} /{ }^{238} \mathrm{U}$ and another at a higher ratio-were desirable for system calibration in order to encompass anticipated ratios of ${ }^{235} \mathrm{U} /{ }^{238} \mathrm{U}$ seen in the field. Analytical results then could be used to more accurately calculate the ${ }^{235} \mathrm{U} /{ }^{238} \mathrm{U}$ ratio of field samples.

Because of the complexity of the SM pneumatics and valving, the use of solenoid valves was preferred for automated operation (Figure 3 ) to ensure reproducibility of sample and standard introduction and precise incorporation of the $\mathrm{CO}_{2}$ mixing gas. Three candidate solenoid valves,

- Brooks V122 proportional control valve,

- MKS 248A proportional control valve, and

- Gems AS 2012 solenoid valve,

were tested by personnel at the ORNL $\mathrm{UF}_{6}$ Test Loop. These tests included leak from the atmosphere, leak across the seat after $n(n=10,25,100)$ on-off cycles during exposure to $\mathrm{UF}_{6}$, and $\mathrm{N}_{2}$ leak across the seat after completion of all cycles. As all valves qualified in the testing, the decision was made to purchase and incorporate the Gems valves, as they were the most economical option.

A Siemens programmable logic controller (PLC) was added to the SM to automate sequencing of the solenoid valves. The PLC was programmed to initiate the valve sequences for each of the sequence functions shown in Table 2, which were used to prepare the SM for operation, mix the standard(s) or sample with $\mathrm{CO}_{2}$, introduce the mix to the MS, clear the SM and MS of residual $\mathrm{UF}_{6}$, and enter an SM shutdown mode.

A system for an $\mathrm{N}_{2}$ fill of the manifold at shutdown was added to ensure maintenance of a dry system during downtime and storage so as to minimize formation of $\mathrm{HF}$ from any residual $\mathrm{UF}_{6}$ interaction with water vapor.

The SM was completed with programming of the PLC for automated operation of the unit (Figure 4).

Upon completion of system checkout, the SM was placed under vacuum and the pneumatics were heated to remove water vapor and any other volatile impurities and to ensure a clean, dry system prior to operation. The estimated weight of the SM is 75 lbs. 


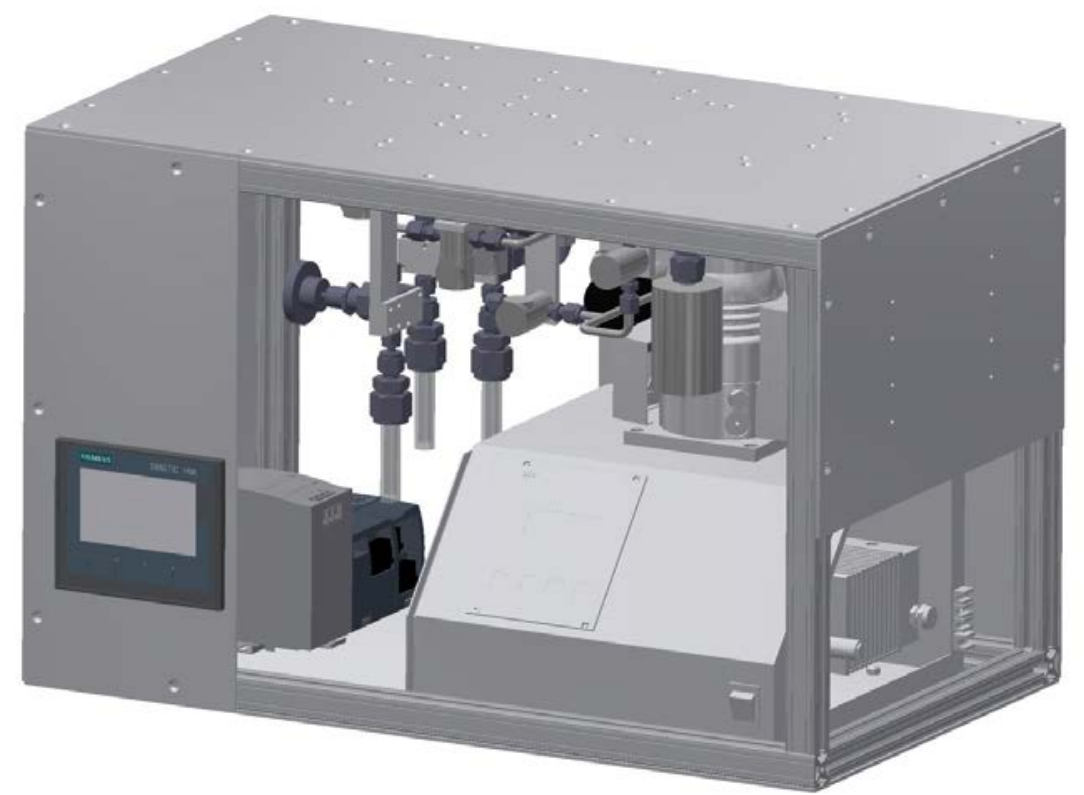

Figure 2. Sample manifold design projection.

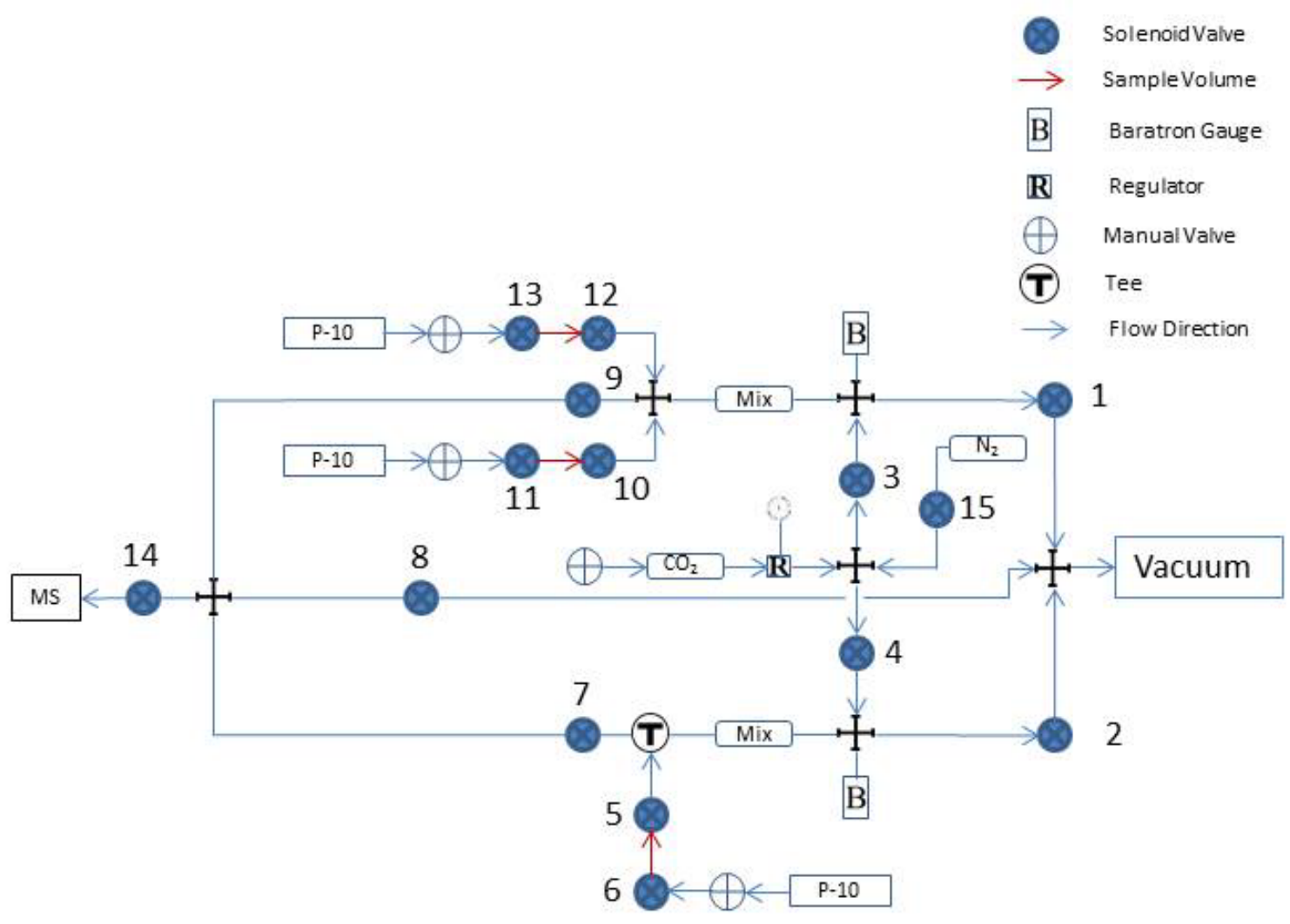

Figure 3. Process flowchart of sample manifold pneumatics. 
Table 2. PLC sequences for valve control and sample manifold operation

\begin{tabular}{|c|c|c|c|c|c|c|c|c|c|c|}
\hline $\begin{array}{l}\text { Sequence } \\
\text { Function }\end{array}$ & Sequence 1 & $\begin{array}{c}\text { Time/ } \\
\text { Condition }\end{array}$ & Sequence 2 & $\begin{array}{c}\text { Time/ } \\
\text { Condition }\end{array}$ & Sequence 3 & $\begin{array}{c}\text { Time/ } \\
\text { Condition }\end{array}$ & Sequence 4 & $\begin{array}{c}\text { Time/ } \\
\text { Condition }\end{array}$ & Sequence 5 & $\begin{array}{c}\text { Time/ } \\
\text { Condition }\end{array}$ \\
\hline $\begin{array}{l}\text { Vacuum } \\
\text { Clearance }\end{array}$ & $\begin{array}{l}\text { Open 1, 2, 5, } \\
7,8,9,10, \\
12 .\end{array}$ & 0.01 mTorr & Close All & & & & & & & \\
\hline $\begin{array}{l}\text { HF } \\
\text { Removal }\end{array}$ & $\begin{array}{l}\text { Open } 1,2,5, \\
10,12\end{array}$ & & $\begin{array}{c}\text { Pulse } 6,11 \text {, } \\
13\end{array}$ & $50 \mathrm{~ms}$ & $\begin{array}{c}\text { Pulse } 6,11 \text {, } \\
13\end{array}$ & $100 \mathrm{~ms}$ & $\begin{array}{c}\text { Pulse } 6,11 \text {, } \\
13\end{array}$ & $250 \mathrm{~ms}$ & $\begin{array}{c}\text { Open } 6,11 \text {, } \\
13\end{array}$ & 0.01 mTorr \\
\hline Sample Mix & Open 6 & $3000 \mathrm{~ms}$ & $\begin{array}{c}\text { Close } 6, \\
\text { Open } 5\end{array}$ & $3000 \mathrm{~ms}$ & $\begin{array}{c}\text { Close } 5, \\
\text { Open } 4\end{array}$ & $65 \mathrm{~ms}$ & Close 4 & & & \\
\hline $\begin{array}{l}\text { Sample to } \\
\text { MS }\end{array}$ & Open 7, 14 & $5 \mathrm{~min}$. & Close 7,14 & & & & & & & \\
\hline $\begin{array}{l}\text { Sample } \\
\text { Cleanout }\end{array}$ & Open $5,7,14$ & & Pulse 2 & $\begin{array}{c}50,100, \\
250 \mathrm{~ms}\end{array}$ & Open 8 & 0.01 mTorr & Close All & & & \\
\hline $\begin{array}{l}\text { Standard } 1 \\
\text { Mix }\end{array}$ & Open 11 & $3000 \mathrm{~ms}$ & $\begin{array}{c}\text { Close } 11, \\
\text { Open } 10 \\
\end{array}$ & $3000 \mathrm{~ms}$ & $\begin{array}{c}\text { Close } 10, \\
\text { Open } 3 \\
\end{array}$ & $65 \mathrm{~ms}$ & Close 3 & & & \\
\hline $\begin{array}{l}\text { Standard } 1 \\
\text { to MS }\end{array}$ & Open 9,14 & $5 \mathrm{~min}$. & Close 9, 14 & & & & & & & \\
\hline $\begin{array}{l}\text { Standard } \\
\text { Cleanout }\end{array}$ & $\begin{array}{l}\text { Open } 9,10 \text {, } \\
12,14 \\
\end{array}$ & & Pulse 1 & $\begin{array}{l}50,100, \\
250 \mathrm{~ms}\end{array}$ & Open 8 & 0.01 mTorr & Close All & & & \\
\hline $\begin{array}{l}\text { Standard } 2 \\
\text { Mix }\end{array}$ & Open 13 & $3000 \mathrm{~ms}$ & $\begin{array}{c}\text { Close } 13, \\
\text { Open } 12 \\
\end{array}$ & $3000 \mathrm{~ms}$ & $\begin{array}{c}\text { Close } 12, \\
\text { Open } 3 \\
\end{array}$ & $65 \mathrm{~ms}$ & Close 3 & & & \\
\hline $\begin{array}{l}\text { Standard } 2 \\
\text { to MS }\end{array}$ & Open 9,14 & $5 \mathrm{~min}$. & Close 9, 14 & & & & & & & \\
\hline Shutdown & $\begin{array}{l}\text { Open } 3,4,7, \\
8,9,10,12\end{array}$ & & Pulse 15 & $1000 \mathrm{~ms}$ & Close All & & & & & \\
\hline
\end{tabular}




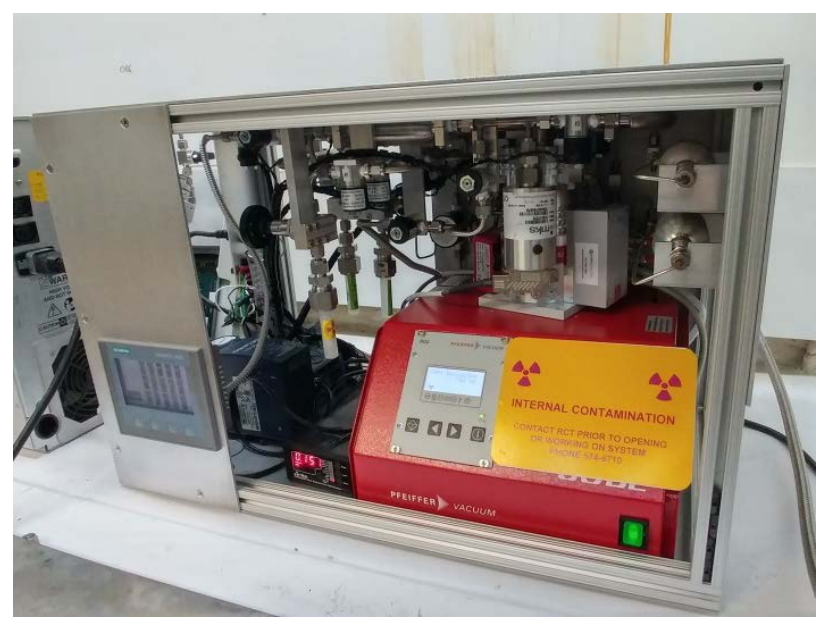

(a)

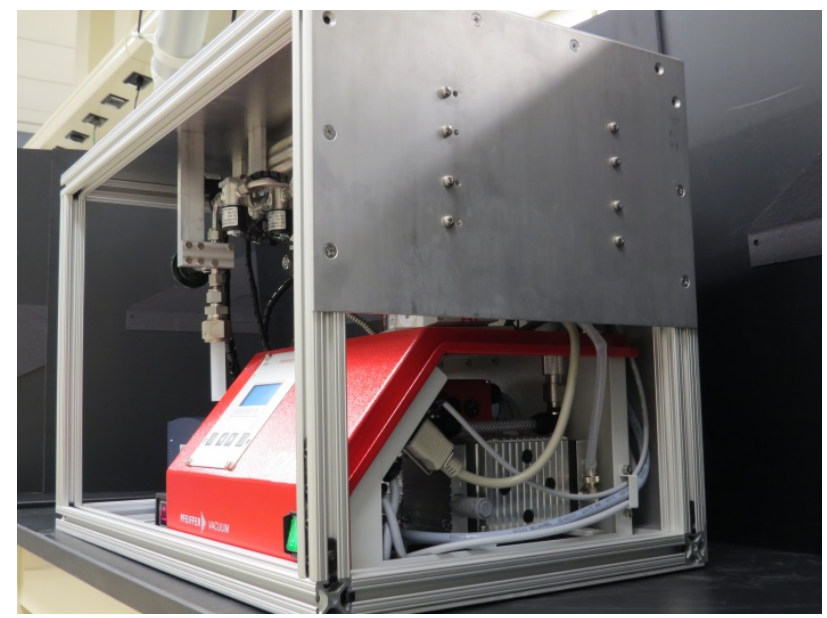

(c)
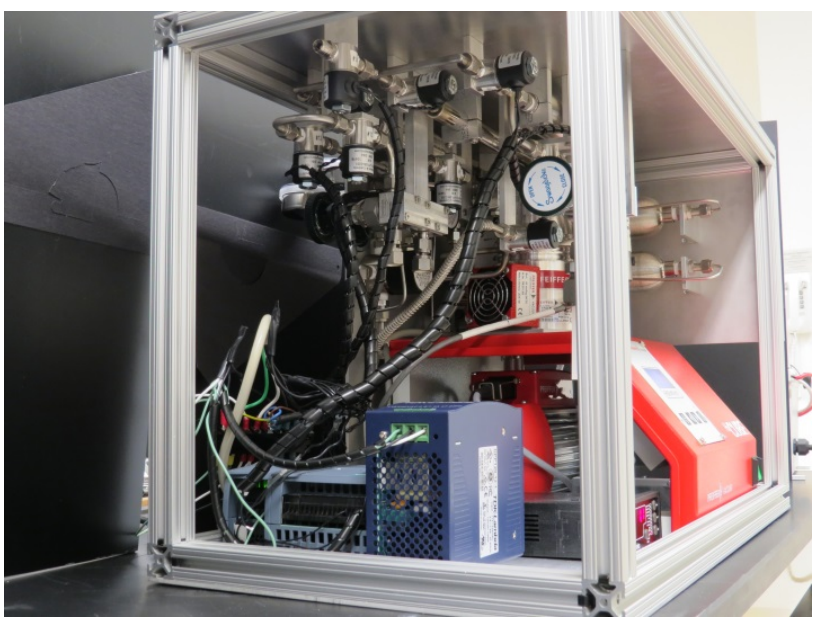

(b)

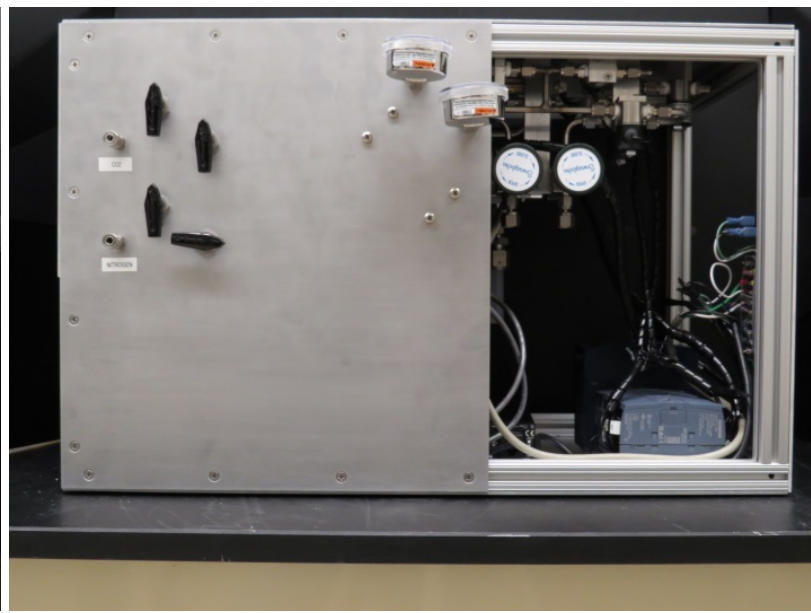

(d)

Figure 4. Sample manifold internals: (a) manifold—front view, (b) manifold—left side view, (c) manifold— right side view, (d) manifold-back view.

Instrument Tuning/Optimization: Due to limited availability of the $\mathrm{UF}_{6}$ test loop systems, a Material Balance Area (MBA) was set up to allow for analysis of $\mathrm{UF}_{6}$ (Figure 5), and experiments for this task were conducted over a period of a month. A total of 46 experiments were completed (Appendix A). 


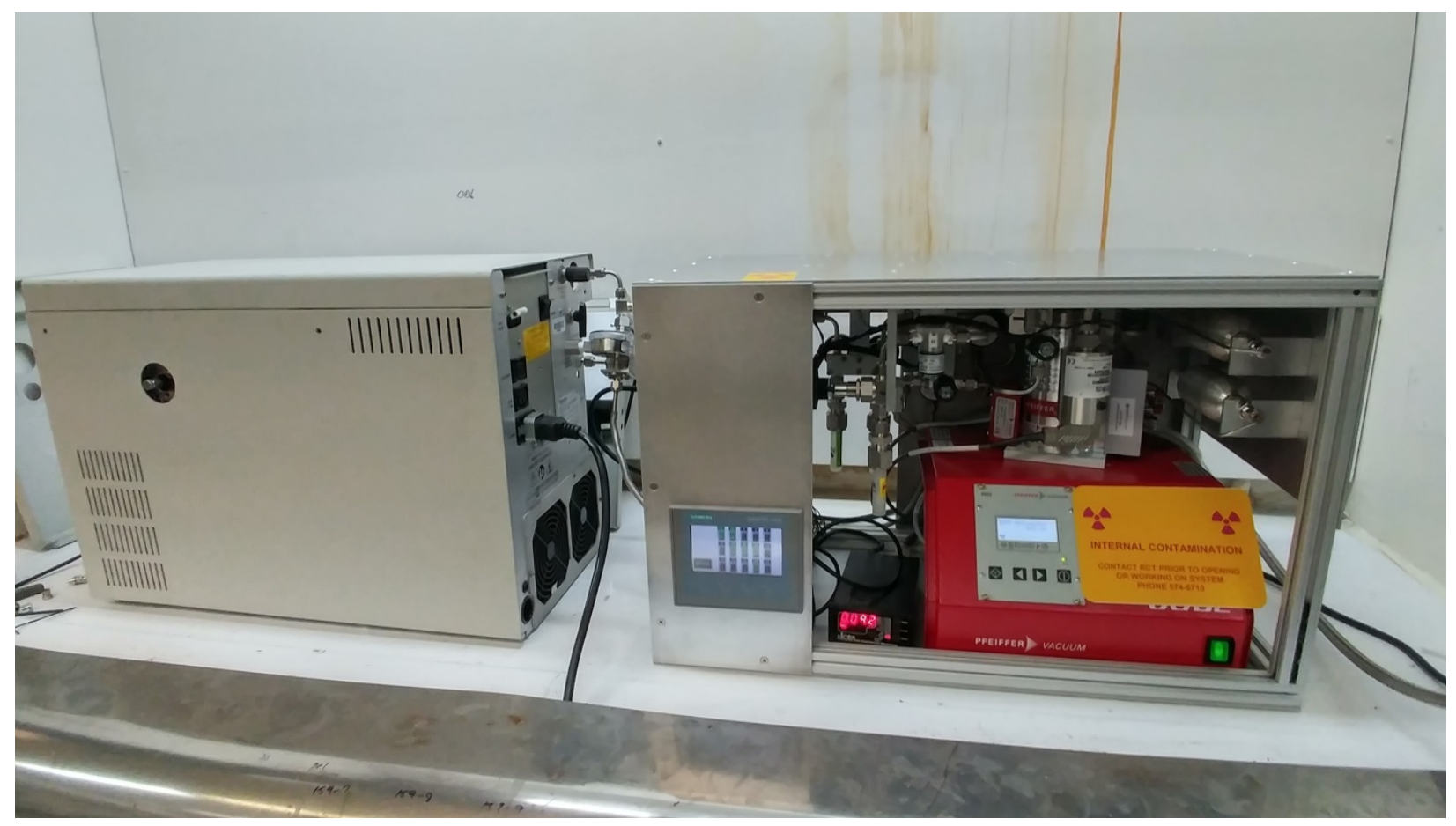

Figure 5. Cart portable MS (left) and sample manifold (right) in MBA hood.

\section{EXPERIMENTAL DESIGN AND TESTING}

The ion volume, as designed by Thermo, is a reaction chamber external to the ion trap analyzer in which the sample is introduced and reacted with either an electron beam or reactant ions generated by an electron beam. For this study, the sample was introduced and reacted with $\mathrm{CO}_{2}{ }^{-}$ions generated by the electron beam. The $\mathrm{CO}_{2}$ gas also moderated (slowed) the electrons in the beam to enhance attachment of the electrons to the $\mathrm{UF}_{6}$. Differences in the ion volumes are the size of the entry port for the electron beam and the size of the exit port for the ion transfer to the analyzer. For CI Ion Volumes, the $\mathrm{e}^{-}$beam entry port is very small (0.016 in.) and the exit port is relatively small (0.032 in.). For EI Ion Volumes, the e beam entry is around $0.062 \mathrm{in}$. and the exit end is fully open (0.368 in.).

The selection of the ion volume did not seem to affect the precision of the instrument as good precision was achieved on all three ion volumes used in experiments. More experiments with the EI ion volume when paired with the MDC Vacuum Products (MDC) sample introduction valve are desirable and might yield a tighter precision for the experiments.

Mass Range: As part of the ITQ's analytical capabilities, the mass range is software selectable to cover any portion of 10-650 amu. The spectral response for $\mathrm{UF}_{6}$ by electron capture negative ECI analysis is in the range of 330-352 amu. Experimental values for the mass range were 200-400, 100-500, 100-650, 50-650, and 30-650 amu. As experimentally determined, wider mass ranges typically yielded less variation in precision with time over the 1 hour period. The ideal mass range for $\mathrm{UF}_{6}$ analysis was found to be 50-650 amu.

Number of Microscans: Each recorded scan of a spectrum in a data file is composed of 1-50 microscans, which are full-spectrum sweeps that are averaged together by the instrument software. 
Experimental values for the number of microscans were 5, 10, 20, and 50. Based on the experimental data, 50 microscans yielded the best instrument precision.

$\mathbf{C O}_{2}: \mathbf{U F}_{\mathbf{6}}$ Ratio: Experimental values of the $\mathrm{CO}_{2}: \mathrm{UF}_{6}$ ratio were 5, 10, and 20. A ratio of 20:1 $\mathrm{CO}_{2}$ to $\mathrm{UF}_{6}$ gave the best precision in the experiments. Ratios of $\mathrm{CO}_{2}$ to $\mathrm{UF}_{6}$ of 30:1 or even 50:1 may improve precision further and should be investigated in the future.

Electron Multiplier (EM) Condition: The EM is the analyzer element most sensitive to the corrosive effects of $\mathrm{UF}_{6}$ and $\mathrm{HF}$. The active surface is composed of a leaded glass which tends to be hygroscopic. The EM manufacturer encourages initial heating of the EM under vacuum for at least an hour to eliminate water vapor which may have accumulated on the active face. This option was not available during the month of experiments due to the use of alternate instrument configurations but should be implemented to improve EM lifetime and stability, which would contribute to better measurement precision.

In the 46 experiments conducted, seven EMs were used. Newly replaced EMs correlated with better measurement precision.

Filament Condition: The MS filament condition did not appear to have an appreciable effect on measurement precision. In fact, the filament was only changed once during the month of experiments. This is a significant improvement over previous experience involving the analysis of $\mathrm{UF}_{6}$ without the addition of $\mathrm{CO}_{2}$, in which filaments often failed after a few days (or less) of use. Filament operation values (electron energy $=70 \mathrm{eV}$, emission current $=250 \mu \mathrm{A}$ ) were the same for all experiments.

Ionization Time: The ionization time is the amount of time the filament is turned on to generate ions in the trap at the beginning of each microscan and is set by the instrument control software.

Variations in ionization time used in these experiments did not appear to affect instrument precision significantly, with the exception that too few ions in the trap greatly increased the variation in precision. Measured values were from 1-16 milliseconds. The best ionization time was found to be 2-

4 milliseconds. The caveat to these observations is that an ionization time which floods the analyzer with too large an ion population will likely cause space charging and lead to loss of peak resolution.

Number of Ions: The ion trap analyzer, which is the heart of the ITQ, is designed to trap a body of ions within a mass-to-charge ratio range selected by the instrument control software. The ion cloud is kinetically cooled with helium gas added to the trap to enable the storage of more ions in the volume of the trap than would normally be permitted without cooling. However, exceeding that limit (estimated to be $5 \times 10^{8}$ ) will cause "space charging" interactions between the ions-in which excess electric charge acts as a continuum over the volume rather than distinct ion charges-leading to reduced mass resolution in the analysis.

The number of ions being analyzed affected the precision (i.e., increased its variation) only when it dipped below $2 \times 10^{6}$ total ion current (TIC). A TIC of $5 \times 10^{6}$ to $4 \times 10^{8}$ seemed to be adequate. Too large a TIC $\left(6 \times 10^{8}\right.$ or greater $)$ affected the peak resolution through space charging.

Helium Pressure: As mentioned above, helium is used in the analyzer to kinetically cool the trapped ions, permitting a greater number to be retained and thereby facilitating an enhanced instrument dynamic range.

Variations in helium pressure (as measured by the instrument ion gauge) in the MS during analysis did not seem to have much effect on the variation in measurement precision. Measured helium pressure values ranged from $7 \times 10^{-6}$ Torr to $2.5 \times 10^{-5}$ Torr. Based on the limited testing for this parameter, a 
suitable value would probably be $\sim 1 \times 10^{-5}$ Torr, to maximize the lifetime of the helium charge in the instrument.

$\mathbf{U F}_{6}$ Sample Pressure: This value is controlled by the "leak" rate of the sample into the MS and affects the number of ions generated as well as the amount of corrosive gas in the analyzer.

Similar to helium pressure, sample pressures also did not appear to have a significant effect on instrument precision variation. Measured sample pressure values ranged from $2 \times 10^{-6}$ Torr to $4.5 \times 10^{-5}$ Torr. Given that a sample pressure of $2 \times 10^{-6}$ Torr yielded an adequate ion population - and that less sample is better, to limit corrosive effects - minimal amounts $\left(2 \times 10^{-6}\right.$ Torr $)$ of sample gas were selected for MS analyses.

Sample Introduction Valve: Several different methods of sample introduction were tested, including a fixed leak using a length of 0.1-mm-ID fused-silica capillary, a Porter fine metering valve, and an MDC MLV all-metal ultra-high-vacuum leak valve. The fixed length capillary was used as the initial method due to its simplicity and ease of replacement. However, it tended to attenuate the amount of sample introduced, possibly due to adsorption/reaction of $\mathrm{UF}_{6}$ by/with the inner capillary surface. The Porter valve was used next, but the slight variations in sample pressure contributed to precision variations. The MDC valve used at a fixed setting proved to be the most stable means of sample introduction. It was left open at a very small, fixed leak value. The sample was introduced to the MS through the MDC sample introduction valve, controlled by the SM, and then removed from the MS by pumping remaining sample away through the SM.

RF Sample and Ramp Rates are parameters controlling the electric field which, in turn, controls (or filters) ions traveling to the analyzer according to their mass-to-charge ratio. These rates were fixed for the entirety of the study as a review of $\mathrm{UF}_{6}$ data collected in the fall of 2015 indicated that the default instrument parameters gave the best results.

Software Development/Data Output: Although the Thermo XCalibur Tune software source code is available, the file format for the *.raw data files generated by the MS is closely held by Thermo. To deal with this, the project workaround, due to the inability to access the data file format, was to develop a rapid post-processing program which would reduce the data and generate the appropriate isotope ratios after completion of the analysis. This program was completed and is ready for use.

\section{RESULTS AND DISCUSSION}

Forty-six experiments (Appendix A) were conducted to optimize instrument and experiment conditions and to determine instrument precision. The variation in precision was calculated by summing the areas for ${ }^{235} \mathrm{UF}_{5}{ }^{-}$and ${ }^{238} \mathrm{UF}_{5}{ }^{-}$for each of the five minute experiments and calculating a ratio of those values, then developing the average and population standard deviation for the sum of the ratios in the six (6) five minute experiments. A reproducible variation in precision of $0.8 \%$ over 1 hour was achieved, with a credible $0.5 \%$ value achieved near the end of experiments. One experiment achieved $0.3 \%$ precision variation over an hour experiment but could not be duplicated within the project deadline (i.e., without further optimization of system operating parameters). Each 1 hour analysis consisted of 5 minutes of sample introduction to the MS followed by 5 minutes of blank, with this sequence repeated five times. The MS was operating continually during the 1 hour experiment. In early experiments, sample introduction was done one time for each experiment, indicated in Appendix A by Fresh or Same in the Sample column. In later experiments, a fresh sample introduction was done for each 5 minute exposure within the experiment. This is indicated in the Sample column by Multi. Figure 6 shows the spectra of ${ }^{235} \mathrm{UF}_{5}{ }^{-}$at $\mathrm{m} / \mathrm{z} 330$ and ${ }^{238} \mathrm{UF}_{5}{ }^{-}$at $\mathrm{m} / \mathrm{z} 333$ from a 1 hour analysis of $3 \%$ enriched $\mathrm{UF}_{6}$. Each spectrum 
represents the sum of the data averaged over 5 minutes of sample introduced to the MS. In this particular experiment, the variation in precision was $0.8 \%$ over the hour of experimentation. Figure 7 shows the ion current intensity for mass-to-charge $(\mathrm{m} / \mathrm{z}) 330\left({ }^{235} \mathrm{UF}_{5}{ }^{-}\right)$and $\mathrm{m} / \mathrm{z} 333\left({ }^{238} \mathrm{UF}_{5}{ }^{-}\right)$during the same experiment. The signal baseline (at zero) between each sample introduction is indicative of a complete lack of response (i.e., response to any between-sample residual during introduction of blank samples) for these masses, as the MS was fully operational throughout the experiment.

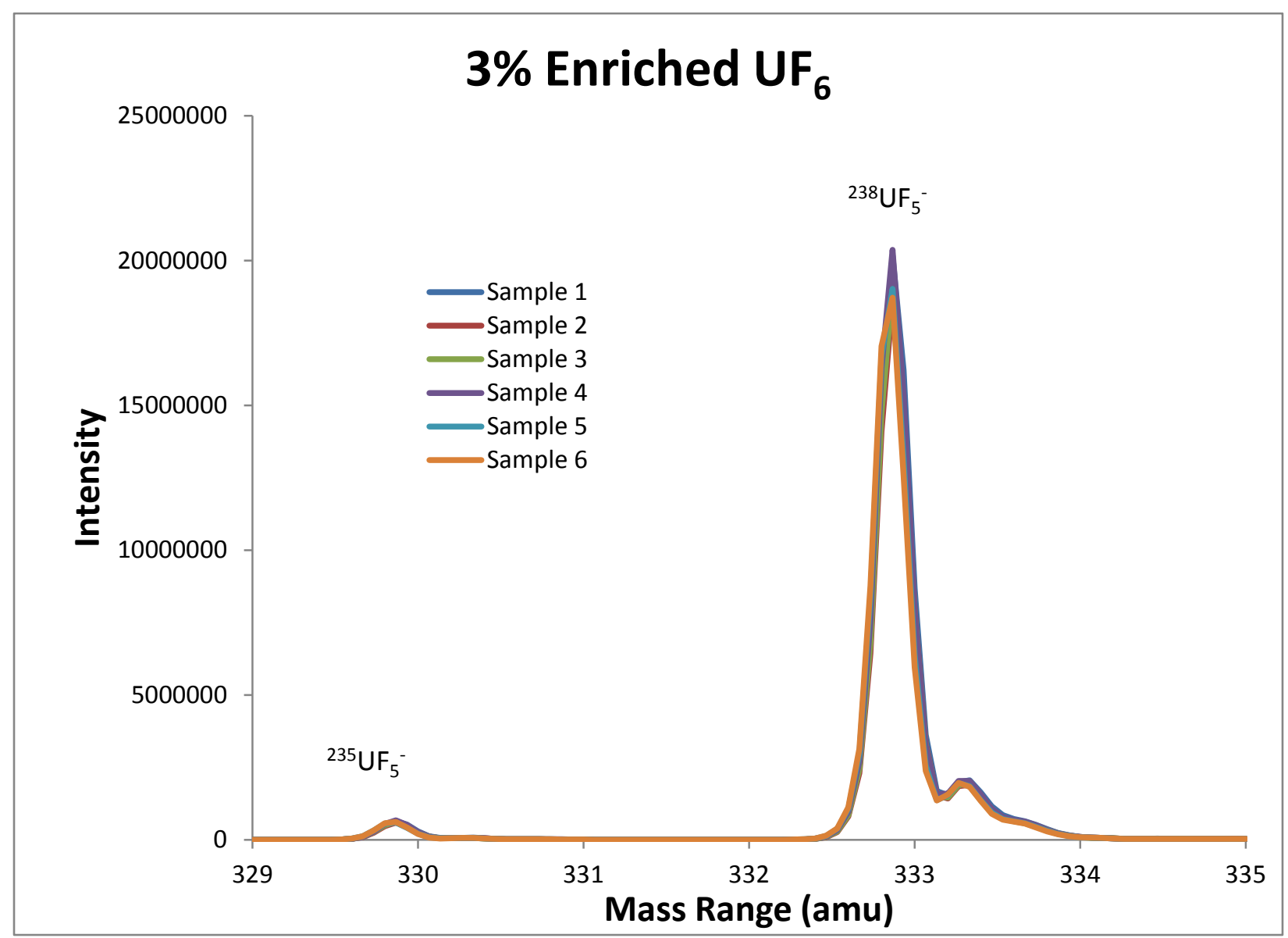

Figure 6. Spectra from 1 hour sample experiment. 


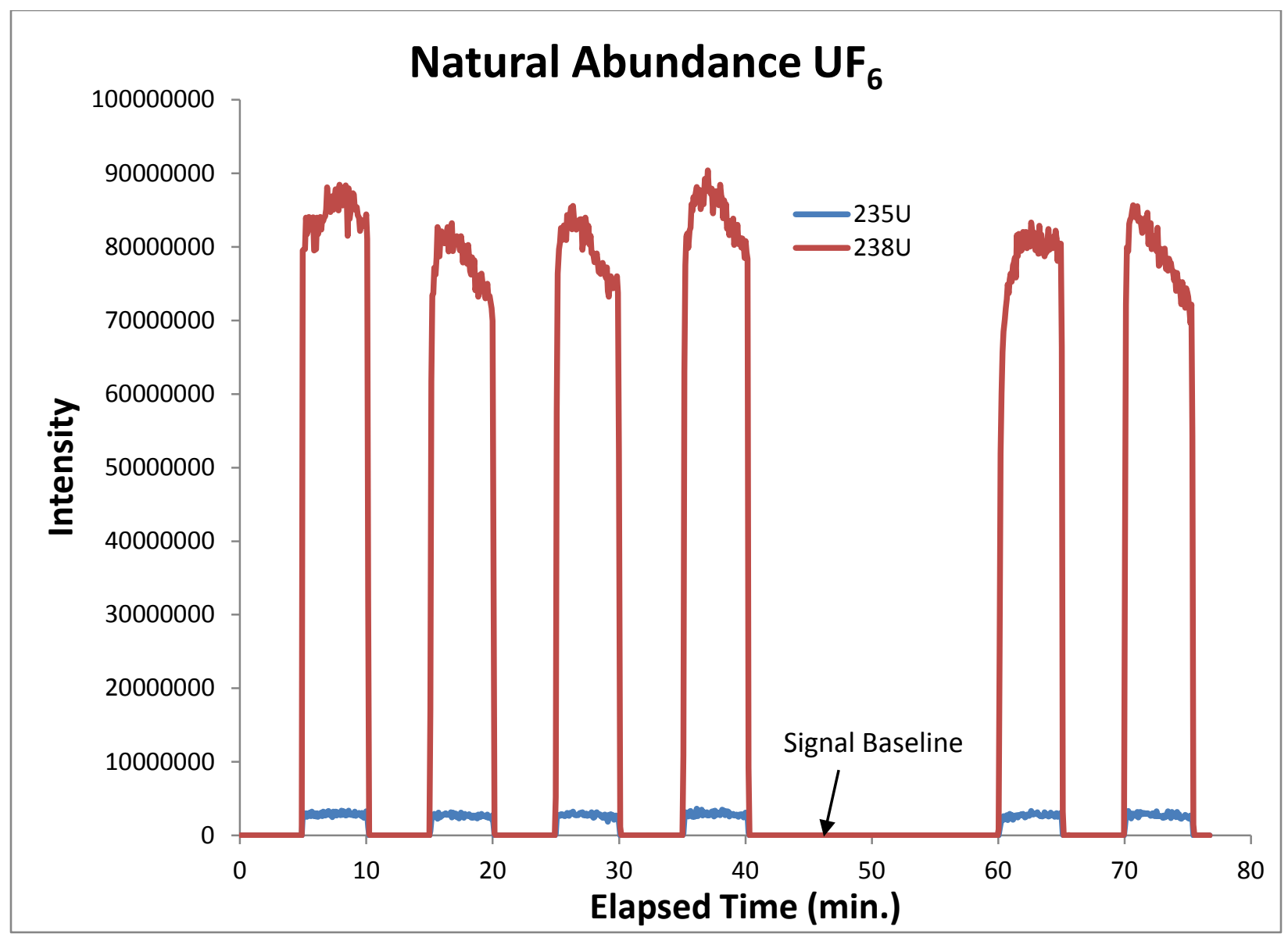

Figure 7. Ion intensity plots for ${ }^{235} \mathrm{U}$ and ${ }^{238} \mathrm{U}$ for 1 hour experiment.

These experiments confirmed the performance of the SM for sample mixing and introduction to the MS. Experiments were also conducted to confirm no sample/standard memory effects or cross-contamination in the SM (Figure 8). As in all other experiments, the MS was continuously operating during this experiment. A baseline response simply indicates the complete absence of the ions of interest - and no sample cross-contamination - during periods of no sample introduction. That is, when a $\mathrm{UF}_{6}$ sample is removed from the manifold, it is completely undetectable.

In addition, the ease of use of the SM is such that once the sample and standards are in place, all other operations can be fully automated. For instance, a sequence can be initiated simultaneously on the MS and the SM such that a blank is acquired on the MS, followed by a 5 minute exposure to a standard from the SM, followed by another blank, followed by a 5 minute exposure to a sample from the SM, and completed by another blank/separate standard/blank sequence. This overall experiment can be repeated several times if desired. An operator can place the sample and standards on the SM, initiate the sequence on the instrumentation, and return 1 hour later when the whole sampling and analysis process is complete.

Using the timing sequences available on the PLC, very precise and reproducible aliquots of $\mathrm{UF}_{6}$ and $\mathrm{CO}_{2}$ were introduced into the SM for mixing, followed by analysis by the MS for all the experiments in this study. 


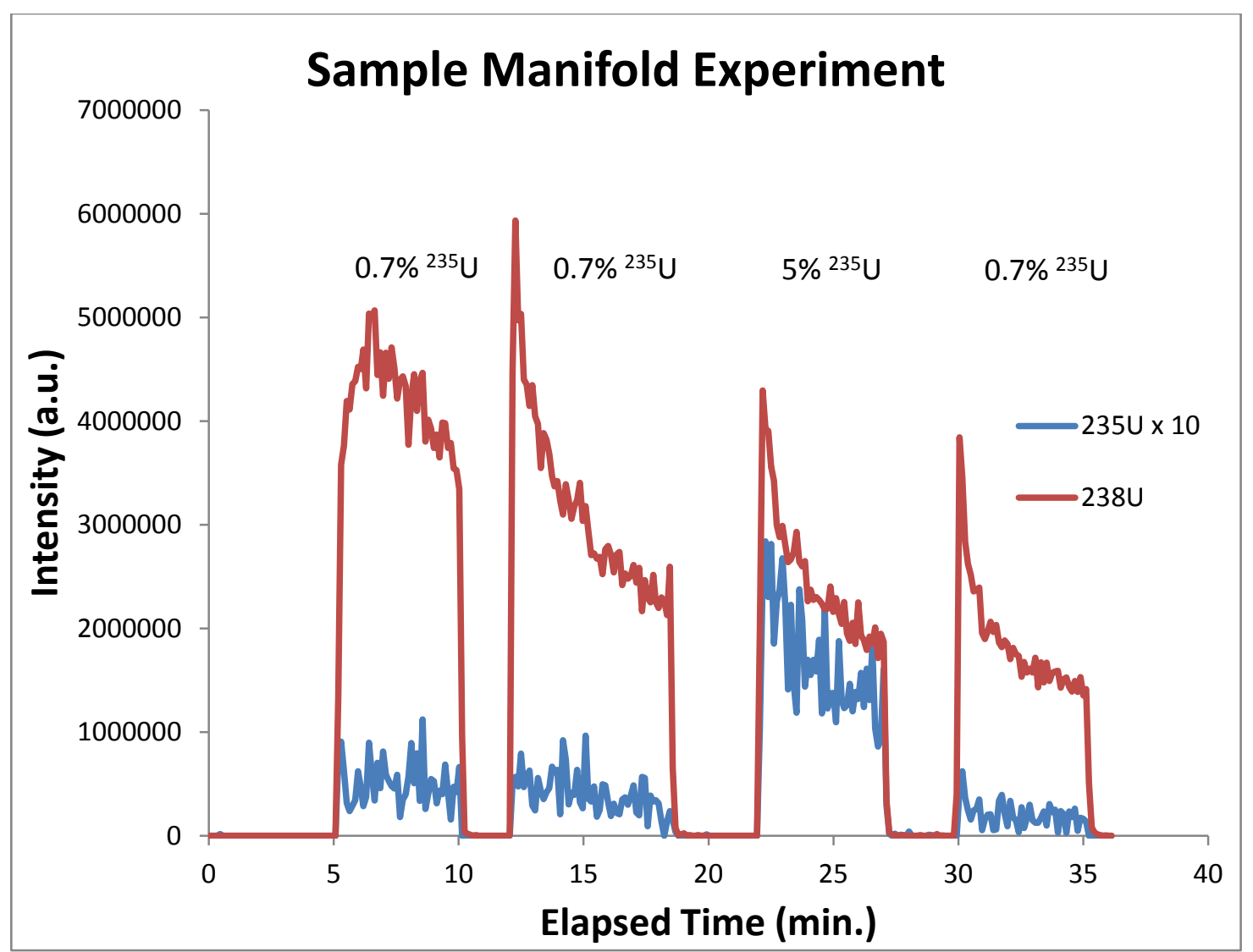

Figure 8. Experiment to monitor sample manifold carry-over.

One of the benefits of $\mathrm{UF}_{6}$ analysis by MS/SM is the extremely small amount of sample required. At a sample pressure in the MS of $1 \times 10^{-5}$ Torr, with a dilution factor of 20:1 $\left(\mathrm{CO}_{2}\right.$ to $\left.\mathrm{UF}_{6}\right)$, the amount of $\mathrm{UF}_{6}$ input into the MS in a 5 minute sample cycle is approximately $10 \mu \mathrm{g}$.

\section{PATH FORWARD}

The project schedule did not allow full characterization of all parameters which affect instrument precision. Several experimental variables would benefit from more characterization and may help drive the variation in analytical precision well below the $0 / 5-0.8 \%$ currently achieved on a reliable basis:

1. The EI ion volume may provide better results than were initially indicated in experiments in which it was used.

2. The EM effects on precision are not fully understood. EM behavior in the 46 experiments was more variable than expected and may be indicative of either variations in individual units or perhaps lack of conditioning prior to actual use.

3. Chamber heating effects (benefits of removal of water vapor from surfaces and from the EM) should be more fully characterized. 
4. The effects of alumina adsorbent traps in the MS were not fully characterized in this study. They appeared to extend the life of the EM, although the amount of the extension was not determined. They also complicated initial MS pump-down, due to the gradual desorption of water vapor from the adsorbent. Overall, they appeared to be beneficial and their analytical effects and cost/benefits should be studied more fully.

5. Helium introduction through dynode shield to reduce the partial pressure of neutral $\mathrm{UF}_{6}$ in this portion of the vacuum chamber.

6. It was demonstrated that the filament life is extended substantially, and adequately, through the use of a 20:1 ratio of $\mathrm{CO}_{2}: \mathrm{UF}_{6}$ in the sample gas mix. However, the effects of an independent introduction of $\mathrm{CO}_{2}$ bath gas on the filament assembly - an easily implemented feature to extend the filament lifetime further - was not characterized in this study.

\section{SUMMARY}

In conclusion, a commercially available Thermo ITQ MS has been retrofit for field deployment and analysis of $\mathrm{UF}_{6}$. The unit has a smaller, heated vacuum chamber, an upgraded, low-power pumping system, and a self-contained support gas (helium) system. The system has been tested and operated both in tuning/checkout mode and in analysis of $\mathrm{UF}_{6}$ by negative ECI operation.

A SM has been designed and completed per IAEA specifications for field analysis of $\mathrm{UF}_{6}$ using $\mathrm{CO}_{2}$ mixing gas. The SM includes full automation of gas introduction to the MS for analysis of both $\mathrm{UF}_{6}$ field samples and two distinct $\mathrm{UF}_{6}$ standards. It incorporates low-power solenoid valves and a modular controller and power supplies. Performance of the SM in the laboratory over a month of testing has confirmed that it meets all necessary operating specifications.

All essential tasks have been completed to deliver a cart portable MS and a SM, and the project goal of $1 \%$ or less variation in analytical precision over an hour of sampling has been achieved. Onsite/field analysis and reporting of $\mathrm{UF}_{6}$ isotope ratios can now be accomplished using the combination of MS/SM developed in this project. 


\section{APPENDIX A}

\begin{tabular}{|c|c|c|c|c|c|c|c|c|c|c|c|c|c|c|c|}
\hline Sample & amu & uscans & $\mathrm{CO} 2$ & $\operatorname{EM}(V)$ & $\begin{array}{c}\text { EM } \\
\text { Cond }\end{array}$ & Fil & Ion Vol & $\begin{array}{l}\text { Ion } \\
\text { Time } \\
\text { (ms) }\end{array}$ & $\begin{array}{c}\text { He } \\
\text { (pTorr) }\end{array}$ & $\begin{array}{c}\mathrm{UF}_{6} \\
\text { (pTorr) }\end{array}$ & $\begin{array}{c}\text { Sample } \\
\text { Intro }\end{array}$ & $\begin{array}{c}\text { Sample } \\
\text { Type }\end{array}$ & Valve & $\begin{array}{l}1 \text { Hour } \\
\text { RSD }\end{array}$ & Notes \\
\hline 9-2-16 S1 & $100-500$ & 20 & $20: 1$ & 1300 & New & New & EI & 3 & $1 \times 5$ & $2.3 \times 5$ & Fresh & Nat & Porter & 0.3 & \\
\hline $9-2-16$ S2 & $50-650$ & 20 & $20: 1$ & 1300 & & & EI & 3 & $1 \times 5$ & $2.3 \times 5$ & Same & Nat & Porter & 2.3 & \\
\hline $9-2-16$ S3 & $200-400$ & 20 & $20: 1$ & 1300 & & & EI & 3 & $1 \times 5$ & $2.3 \times 5$ & Same & Nat & Porter & 3.5 & \\
\hline $9-2-16$ S4 & $200-400$ & 20 & $20: 1$ & 1300 & & & EI & 3 & $1 \times 5$ & $2.3 \times 5$ & Fresh & Nat & Porter & 1.7 & \\
\hline 9-6-16 S1 & $50-650$ & 20 & $20: 1$ & 1500 & & & EI & 3 & $1.2 \times 5$ & $2.3 \times 5$ & Fresh & Nat & Porter & & Data File Corrupted \\
\hline $9-6-16$ S2 & $50-650$ & 20 & $10: 1$ & 1500 & & & EI & 3 & $1.2 \times 5$ & $1.7 \times 5$ & Fresh & Nat & Porter & 3 & \\
\hline $9-7-16$ S1 & $50-650$ & 20 & $5: 1$ & 1500 & & & EI & 3 & $1.2 \times 5$ & $1.7 \times 5$ & Fresh & Nat & Porter & 5.2 & \\
\hline $9-7-16$ S2 & $50-650$ & 10 & $20: 1$ & 1500 & & & EI & 3 & $1.7 \times 5$ & $2.2 \times 5$ & Fresh & Nat & Porter & $1.6^{*}$ & \\
\hline $9-7-16$ S3 & $50-650$ & 5 & $20: 1$ & 1500 & & & EI & 3 & $1.7 \times 5$ & $1.2 \times 5$ & Fresh & Nat & Porter & 3 & \\
\hline 9-12-16 S1 & $50-650$ & 20 & $20: 1$ & 1300 & New & & EI & 3 & $1.2 \times 5$ & $1.4 \times 5$ & Fresh & Nat & Porter & 4 & \\
\hline 9-13-16 S1 & $100-500$ & 20 & $20: 1$ & 1300 & & & EI & 3 & $1.1 \times 5$ & $2.5 \times 5$ & Fresh & Nat & Porter & 5.2 & \\
\hline 9-13-16 S2 & $100-500$ & 20 & $20: 1$ & 1300 & & & EI & 3 & $1.1 \times 5$ & $2.5 \times 5$ & Fresh & Nat & Porter & 10.5 & Old PC V1.4 \\
\hline 9-13-16 S3 & $100-500$ & 20 & $20: 1$ & 1300 & & & EI & 3 & $1.5 \times 5$ & $2.1 \times 5$ & Fresh & $3 \%$ & Porter & 7.4 & \\
\hline 9-13-16 S4 & $100-500$ & 20 & $20: 1$ & 1400 & & & EI & 3 & $1.5 \times 5$ & $2.1 \times 5$ & Fresh & $5 \%$ & Porter & 1.3 & \\
\hline 9-14-16 S1 & $50-650$ & 20 & $20: 1$ & 1300 & New & & EI & 3 & $1.6 \times 5$ & $2 \times 5$ & Multi & All & MDC & & Carryover study \\
\hline $9-14-16$ S2 & $50-650$ & 50 & $20: 1$ & 1300 & & & EI & 3 & $1.6 \times 5$ & $2 \times 5$ & None & None & MDC & & Carryover check \\
\hline $9-14-16$ S3 & $50-650$ & 50 & $20: 1$ & 1300 & & & EI & 3 & $1.4 \times 5$ & $2.3 \times 5$ & Multi & Nat, 5\% & MDC & & Carryover study \\
\hline 9-15-16 S1 & $100-500$ & 50 & $20: 1$ & 1300 & & & EI & 3 & $1.1 \times 5$ & $1.9 \times 5$ & Fresh & Nat & MDC & 1.9 & \\
\hline 9-16-16 S1 & $100-500$ & 50 & $20: 1$ & 1500 & & & CI mod & 3 & $1.2 \times 5$ & $1.5 \times 5$ & Fresh & $3 \%$ & MDC & 3 & \\
\hline $9-16-16$ S2 & $100-500$ & 50 & $20: 1$ & 1500 & & & CI mod & 3 & $9 \times 6$ & $9 \times 6$ & Multi & $3 \%$ & MDC & 0.8 & $\begin{array}{l}\text { Began using fixed } \\
\text { value on sample } \\
\text { valve }\end{array}$ \\
\hline 9-16-16 S3 & $100-500$ & 20 & $20: 1$ & 1500 & & & CI mod & 3 & $1 \times 5$ & $1 \times 5$ & Multi & $3 \%$ & MDC & 1.3 & \\
\hline 9-19-16 S1 & $100-500$ & 50 & $20: 1$ & 1500 & & & CI mod & 3 & $2.5 \times 5$ & $1 \times 5$ & Multi & $3 \%$ & MDC & 0.8 & \\
\hline 9-19-16 S2 & $100-500$ & 50 & $20: 1$ & 1500 & & & CI mod & 3 & $2.5 \times 5$ & $1 \times 5$ & Multi & $3 \%$ & MDC & 0.8 & \\
\hline 9-19-16 S3 & $50-650$ & 50 & $20: 1$ & 1500 & & & CI mod & 3 & $2.5 \times 5$ & $1 \times 5$ & Multi & $3 \%$ & MDC & 0.5 & \\
\hline 9-20-16 S1 & $50-650$ & 50 & $20: 1$ & 1300 & New & & CI mod & 3 & $1.2 \times 5$ & $1 \times 5$ & Multi & $3 \%$ & MDC & 4 & \\
\hline $9-20-16$ S2 & $50-650$ & 50 & $20: 1$ & 1300 & & & CI mod & 1 & $1.2 \times 5$ & $1 \times 5$ & Multi & $3 \%$ & MDC & 1.6 & \\
\hline
\end{tabular}




\begin{tabular}{|c|c|c|c|c|c|c|c|c|c|c|c|c|c|c|c|}
\hline Sample & amu & uscans & $\mathrm{CO} 2$ & EM & $\begin{array}{c}\text { EM } \\
\text { Cond }\end{array}$ & Fil & Ion Vol & $\begin{array}{l}\text { Ion } \\
\text { Time } \\
\text { (ms) } \\
\end{array}$ & $\begin{array}{c}\text { He } \\
\text { ( } \mu \text { Torr) }\end{array}$ & $\begin{array}{c}\mathrm{UF}_{6} \\
\text { ( } \boldsymbol{\mu T o r r})\end{array}$ & $\begin{array}{c}\text { Sample } \\
\text { Intro }\end{array}$ & $\begin{array}{c}\text { Sample } \\
\text { Type }\end{array}$ & Valve & $\begin{array}{c}1 \text { Hour } \\
\text { RSD }\end{array}$ & Notes \\
\hline 9-21-16 S1 & $100-500$ & 50 & $20: 1$ & 1300 & & & CI mod & 1 & $1.3 \times 5$ & $1.2 \times 5$ & Multi & $5 \%$ & MDC & 3.6 & \\
\hline $9-21-16$ S2 & $100-400$ & 50 & $20: 1$ & 1300 & & & CI mod & 1 & $1.3 \times 5$ & $1 \times 5$ & Multi & $5 \%$ & MDC & short & \\
\hline $9-21-16$ S4 & $30-650$ & 50 & $20: 1$ & 1500 & & & CI mod & 2 & $1.3 \times 5$ & $1.2 \times 5$ & Multi & Nat & MDC & 2.8 & \\
\hline 9-22-16 NS1 & $100-500$ & 50 & $20: 1$ & 1350 & & & CI mod & 3 & $7 \times 6$ & $3.1 \times 5$ & Multi & $3 \%$ & MDC & 1 & Modified ITQ \\
\hline 9-22-16 NS2 & $100-500$ & 50 & $20: 1$ & 1350 & & & CI mod & 3 & $7 \times 6$ & $2.2 \times 5$ & Multi & $3 \%$ & MDC & 9.2 & Modified ITQ \\
\hline 9-26-16 NS1 & $100-500$ & 50 & $20: 1$ & 1350 & & & CI mod & 3 & $8 \times 6$ & $4.5 \times 5$ & Multi & $3 \%$ & MDC & 4 & Modified ITQ \\
\hline 9-26-16 S1 & $100-500$ & 50 & $20: 1$ & 1500 & & & CI mod & 3 & $1.6 \times 5$ & $1 \times 5$ & Multi & $3 \%$ & MDC & 5.3 & \\
\hline 9-28-16 S1 & $100-500$ & 50 & $20: 1$ & 1300 & New & New & CI mod & 3 & $1.9 \times 5$ & $1.4 \times 5$ & Multi & $3 \%$ & MDC & $(2.6)$ & $30 \mathrm{~min}$ \\
\hline 9-28-16 S2 & $100-500$ & 50 & $20: 1$ & 1300 & & & CI mod & 3 & $1.9 \times 5$ & $1.8 \times 5$ & Multi & $3 \%$ & MDC & 2 & \\
\hline 9-28-16 S3 & $100-500$ & 50 & $20: 1$ & $1300 / 1500$ & & & CI mod & 2 & $2.1 \times 5$ & $1.6 \times 5$ & Multi & $3 \%$ & MDC & 3.2 & abbrev \\
\hline $9-28-16$ S4 & $100-500$ & 50 & $20: 1$ & 1400 & New & & CI mod & 2 & $2.3 \times 5$ & $2 \times 6$ & Multi & $3 \%$ & MDC & 2.6 & \\
\hline 9-29-16 S1 & $100-500$ & 50 & $20: 1$ & 1400 & & & CI mod & 2 & $1.8 \times 5$ & $3 \times 6$ & Multi & $3 \%$ & MDC & 1.9 & \\
\hline 9-29-16 S2 & $100-500$ & 50 & $20: 1$ & 1400 & & & CI mod & 2 & $2.3 \times 5$ & $5 \times 6$ & Multi & $3 \%$ & MDC & 1.4 & \\
\hline 9-29-16 S3 & $100-650$ & 50 & $20: 1$ & 1400 & & & CI mod & 3 & $2 \times 5$ & $5 \times 6$ & Multi & $3 \%$ & MDC & 6.1 & \\
\hline $9-29-16$ S4 & $100-650$ & 50 & $20: 1$ & 1500 & & & CI mod & 3 & $2.3 \times 5$ & $5 \times 6$ & Multi & $3 \%$ & MDC & & Data File Corrupted \\
\hline 9-30-16 S1 & $100-500$ & 50 & $20: 1$ & 1300 & New & & $\mathrm{EI} / \mathrm{CI}$ & 3 & $2.2 \times 5$ & $5 \times 6$ & Multi & $3 \%$ & MDC & 2.7 & \\
\hline 9-30-16 S2 & $100-500$ & 50 & $20: 1$ & 1300 & & & $\mathrm{EI} / \mathrm{CI}$ & 3 & $2.2 \times 5$ & $3 \times 6$ & Multi & $3 \%$ & MDC & 1 & \\
\hline 9-30-16 S3 & $100-500$ & 50 & $20: 1$ & 1300 & & & $\mathrm{EI} / \mathrm{CI}$ & 3 & $2.2 \times 5$ & $3 \times 6$ & Multi & $3 \%$ & MDC & 1.8 & \\
\hline $9-30-16$ S4 & SIM & 50 & $20: 1$ & 1300 & & & $\mathrm{EI} / \mathrm{CI}$ & 3 & $2.2 \times 5$ & $3 \times 6$ & Multi & $3 \%$ & MDC & 6.7 & $\begin{array}{l}\text { Single Ion } \\
\text { Monitoring +/- } 1\end{array}$ \\
\hline 9-30-16 S5 & SIM & 50 & $20: 1$ & 1300 & & & $\mathrm{EI} / \mathrm{CI}$ & 3 & $2.2 \times 5$ & $9 \times 6$ & Multi & $3 \%$ & MDC & $(0.8)$ & $\begin{array}{l}\text { Single Ion } \\
\text { Monitoring +/- } 0.5 \\
\text { (over } 40 \text { min.) }\end{array}$ \\
\hline
\end{tabular}

